\title{
Intermodal transportation of full and empty containers in harbor-inland regions based on revenue management
}

\author{
Zixuan Peng ${ }^{1,2}$, Huaizhu Wang ${ }^{1,3}$, Wensi Wang ${ }^{1}$ and Yonglei Jiang ${ }^{1 *}$
}

\begin{abstract}
Introduction: The transport of full containers and repositioning of empty containers are essential for the operation of a container logistic enterprise. In a large inland region, railway and road transportation take their own advantages for container transportation in terms of transport efficiency and costs. The combination of the two modes creates larger possibility for logistic enterprise to provide efficient service and reduce operation costs. Thus, this paper aims to optimize the inland intermodal transportation of full and empty containers.

Methods: Different from cost minimum model, an integer programming model is proposed based on revenue management, making the model more reasonable in practice where logistic enterprises have the right to reject transportation demands from customers considering transport profits and capacity limitations. The real cases of transportation networks of Northeast China and parts of the southern Europe are applied to evaluate and describe the model and performance.

Results: The results indicate that the proposed intermodal transportation optimization for both full and empty containers is feasible and profitable for logistic enterprises. The efficiency of container usage increases since we take the conversion of containers during transportation into account. Results also imply an inappropriate pricing strategy at certain inland depots in the case.

Conclusions: This paper provides an optimization method for the intermodal transportation of full and empty containers in harbor-inland regions / hinterlands. Different from cost minimization in the literature, this paper models the transportation problem based on revenue management. That is, the model aims to maximize profits of logistic enterprise with the specific constraints in container transportation, as well as demand rejection. The model is proofed to be feasible in the real transportation networks and can create more profits for transportation enterprises. The analysis of real cases show that the total profits can be enlarged by considering the conversion of containers during transportation. In addition, it is verified that the optimization of inland transportation of empty and full containers reduces the operating costs of logistic enterprises. Moreover, results uncover the fact that a governed pricing policy at Suifenhe is not reasonable and may deteriorate the future export environment there. For the case based on part of southern Europe, it seems that the port, customer, inland transport operator and possibly container shipping company in Europe may benefit by establishing appropriate inland depots.
\end{abstract}

Keywords: Intermodal transportation, Inland container transportation, Repositioning of empty containers, Logistics optimization model

*Correspondence: jiangyonglei@dlmu.edu.cn

${ }^{1}$ Transportation Management College, Dalian Maritime University, Dalian

116026, People's Republic of China

Full list of author information is available at the end of the article 


\section{Introduction}

The road freight transport is successful in in Europe, but it also brings congestion and environmental problems. The European Conference of Ministers of Transport (ECMT) proposes the intermodal transport for the sustainability. Container, as a standard equipment that designed for convenient transportation, is a main tool for the transportation of international cargos. Meanwhile, container ships, container railway and container trucks appear and ensure the convenience of container transportation. Benefitting from the standard containers which can be transferred easily between multiple transportation modes (e.g., railway, sea and road transportation), intermodal transportation has extended the distance of cargo transportation greatly through door-to-door (DTD) pattern. In addition, the development of inland cities stimulates the need for convenient and fast transportation because of geographical weakness of inland cities (e.g., too far from coast) in international trades. Since inland cities usually play the role of feeders of the harbors nearby, the regions are referred to as hinterlands of some harbors/ports. The increasing demand for convenient and fast transportation motivates the pattern of DTD, and from DTD pattern, transportation enterprises can collect more cargos/containers from hinterlands. For example, the port of Barcelona improves inland transport network to connect the hinterlands. The market outside the Iberian peninsula is developed by the railway transport. Container transportation, however, generates the issue of empty containers movements in back-haul transport (e.g., repositioning of empty containers in DTD). Europe is one of the common shortage areas of empty containers while it also a surplus area at different times or for different types of containers. Countries such Germany, France and Belgium import the raw materials and fuels of industry and then export their products. The trades in Europe is imbalanced. Moreover, owing to the imbalance of economy developments in different inland regions/cities, flows of full and empty containers in these regions are also imbalanced. Thus, in a specific region the phenomenon of imbalanced cargo flows also exists because of inner imbalances in the region. A large quantity of empty containers needs to be transported between inland depots and harbors for recycle use and most important for maintaining balance. As for the cities in Northeast China, the role that each city plays differs from each other in international trades. In detail, some cities have relatively developed manufacture industry and need a large quantity of inbound materials, referred to as import cities, while many cities has more cargos to export such as textile and garment export cities, referred to as export cities. Different roles of cities lead to great gaps between the quantity of imports and exports, and the gaps generate the imbalance of containers flows for a container transportation enterprise. That is, imported containers will be transported to importers in a city and after discharging these empty containers might be surplus for this city, while other cities have large demands for these empty containers to transport their exported cargos. The issue of imbalance motivates the transportation enterprise to reposition surplus empty containers in its service region, e.g., hinterlands.

Transportation of containers comprises ocean-going transportation and transportation on land. Ocean-going transportation is mainly focused on by its shipping networks, known as the design of shipping network $[6,16,18,20]$. Compared with the long-haul transport on the sea, inland transportation of containers is relatively shorter but the issue of inland container transportation is also considerably discussed and studied in literature.

As for sea-going container transportation, [15] discussed the optimal routing problem for a fleet of container ships that operated on a shipping route, to maximize the total profits of a liner shipping enterprise. Bendall and Stent [3] proposed a model to determine the optimal fleet and the corresponding fleet deployment plan in a short-haul hub and spoke feeder operation. Considerable research is also been performed in the issue of transportation of empty containers since empty containers are essential to narrow the potential operating costs.

For the empty-flow problem of containers, [8] proposed a tabu search heuristic in a multi-commodity network, while the routing of full containers is not taken into account. Moreover, empty containers are considered in the shipping network [9, 10, 17], which aim to relocate empty containers in the network to achieve an equilibrium for customer's demands. Similarly, [1] extended the problem into inland waterway with a model for the network design of containers lines.

In terms of inland container transportation, the issue is commonly regarded as an extension of vehicle routing problem (VRP). Min [11] developed a chance-constrained model that aims to minimize transport cost and risk. [7] investigated a container drayage operation with the present and future operating costs minimized. Additionally, repositioning of empty containers is considered in many literature. Olivo et al. [13] proposed an operational model for the management of inland empty containers in the Mediterranean basin. Empty containers are focused on and optimization of empty containers resources is conducted. Namboothiri and Erera [12] studied a management problem of a fleet of trucks that provide transportation service of containers to a port, where empty or full containers are not clearly distinguished because the two types can be classified into transportation service generally. 
Actually, the demand of empty containers is derived from transporting full containers in the inland networks. Satisfying the requests for full containers punctually could improve the quality of the service for operators. Meanwhile, the storage of empty containers is also a guarantee for up-coming transportation of full containers. Therefore, delivery and collection of full containers, as well as repositioning of empty containers are integrated and solved in the literature. Yao et al. [19] used an improved particle swarm optimization solve a carton heterogeneous vehicle routing problem with a collection depot. Thus, they can attempted to avoid empty containers. Zhang et al. [21] studied four types of movements of containers as inbound full, outbound full, inbound empty and outbound empty movements as well as the time windows by trucks.

Concurrently, both full and empty containers are considered together. Empty containers are considered both in sea-going $[9,10,17]$ and inland transportation (refer to as repositioning of empty containers), not only the transportation of full containers. Numerous researches are performed to discuss, analyze and cope with the problems in inland transportation of containers, e.g., location of inland depots and VRP of containers.

The objective function in most research is to minimize transportation costs, where vehicles need to satisfy the preset transportation demand. However, not all transportation demand from customers will be satisfied in practice. In other words, part of the demand could be rejected/abandoned by logistic enterprises because of their limited transport capacity. Thus, the alternative objective for the issue is maximizing profits (revenue minus cost), in which transportation enterprise might reject customer's demand in case of the conflict between profits and capacity. Hence, in this paper, the proposed model aims to maximize the total profits of the transportation enterprise, which serves for the customers in hinterland who have inbound or outbound demands. Both trains and trucks are applied to finish cargo transportation, that is, intermodal transportation in hinterland based on revenue management (profit maximization).

In terms of transportation vehicle, an array of studies on inland transport of containers concentrates on transportation by trucks, which indicates that this kind of transportation should not be long-haul ones considering the efficiency of trucks in costs. The short-haul transportation can be well done in a small-scale hinterland by container trucks owing to truck's flexibility. However, if the hinterland is large (e.g., with a transportation distance larger than 1000 kilometers), trucks seem to be inefficient and costly, while railway could be the alternative way for container transportation. The issue of container transportation by trucks is fully studied but as for the long-haul container transportation in hinterland, it is still interesting to optimize [5], especially for the inland-intermodal transportation of full and empty containers, e.g., transporting by both trains and trucks. Arnold et al. [2] formulated the problem of locating inland depots of rail and road transportation. That is, both of railway and road transportation are taken into account in the inland transportation of containers to minimize total transportation costs. In addition, depots are proved that it can reduce transportation cost owing to scale economies effect. Boile et al. [4] proposed a system of inland depots for empty containers (IDEC). They analyzed that the inland depots could reduce the empty vehicle miles traveled and the cost of repositioning empty containers.

The remainder of the paper is organized as follow. Section 2 introduces the problem to be optimized, and an integer programming is proposed for the inland transportation problem in Section 3. The real cases of transportation networks of Northeast China and parts of the southern Europe are applied to evaluate the proposed model in Section 4. Section 5 draws the general conclusion of the study.

\section{Problem description}

A container transportation enterprise usually has a service coverage, and in this coverage there exists many customers that have international business operations, which motivates the transportation of cargos spatially. The container transportation enterprise serves customers, transports and charges for customers' imported or exported cargos. Specifically, the enterprise transports importcargos (full containers) from harbors to customers' appointed places on receipt, and transports export-cargos (full containers) from customers' location to harbors. Transporting full containers is a profitable operation for enterprises, however, empty containers are also of essence and cannot be neglected owing to the conversion of containers. For example, full-import containers will convert to empty containers after discharging at customers' location, which is referred to as the conversion of container status in the remaining of the paper. Thus, empty containers will be collected to depots for the use of outbound/ exported cargos. For the service network of a container transportation enterprise (see Fig. 1), empty containers need to be repositioned because of the upcoming imbalanced demands of transportation.

Full containers from overseas transported by container ships are unloaded at harbors and transportation enterprise transports the containers from harbors to different depots by railway. That is, a transportation enterprise usually owns many inland depots to gather or deliver containers at inland cities. Full-import containers will be transported from harbors to these depots and then be delivered to each customer. Trains 

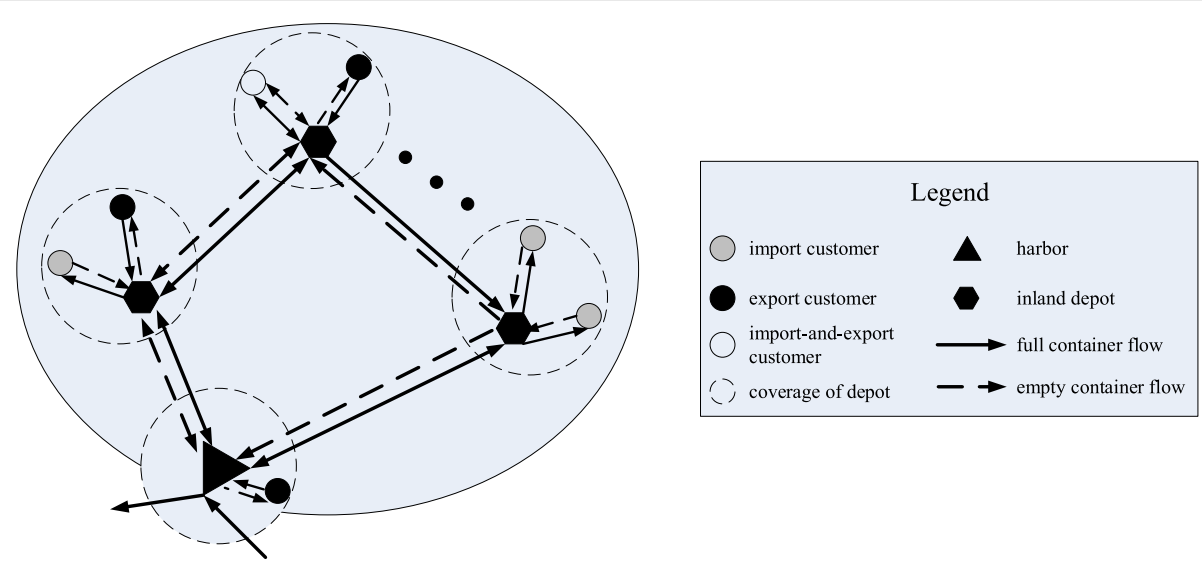

Fig. 1 Transportation network of container

and container trucks are commonly used for the movements of containers, where usually railway for long-haul movements (e.g., movements between depots) and trucks for short-haul movements (e.g., movements between depots and customer's locations). Full-imported containers are delivered from harbor to the depots by trains and then transported to customers by container trucks. Once the imported containers arrive at destinations and are discharged/unlocked, these empty containers will be returned to depots where they come from.

On the one hand, empty containers in each depot will be provided to the served customers who have demand for exporting. On the other hand, repositioning of empty containers should be conducted between depots (harbors are also regarded as depots) to rebalance the distribution of empty containers in the whole service network corresponding to transportation demand. Since the ownedcontainers of a transportation enterprise is usually fixed in a short time horizon, the alternative way to rebalance empty containers of a enterprise is leasing empty containers from other transportation enterprises. In practice, empty containers usually have a limit for leasing time span (e.g., more than one month) so that transportation enterprise commonly will not lease a lot of containers unless a rapid increase of customer's demand in a short time. Otherwise, enterprise will undertake unnecessary leasing cost. Figure 1 illustrates the transportation network of a container transportation enterprise.

In this logistic network, there are two enterprises which provide transportation service. One enterprise (A) is the logistic company that offers its transportation service to customers and the other one is the railway company (B) which offers railway transportation. Cargos from customers will be collected by A, and B will help A transport cargos by railway for paid service. Railway in the case study is owned by the state, so that no logistic enterprise can use trains directly without the stateoperated railway company. Transportation by railway has a fixed freight rate table given by the railway company so that there is no gaming between the two enterprises if discount for large-volume transport is not considered. In this system, various logistic enterprises are not considered, which means the model take one logistic enterprise's operation into account. Three kinds of transport vehicles are inclusive in the system, that is, ships, trains and trucks. Trains and trucks are the two main vehicles that considered in the model and the case. For long haul transportation, cargos are set to be transported by trains and relatively short transportation is finished by trucks.

\section{Formulation}

\subsection{Assumptions}

To simply the formulations of the problem and upcoming analysis, assumptions should be clarified, all of which are common in the literature.

- A closed system. Only three participants exist in the proposed problem, that is, harbors, inland depots and customers served by depots or harbors. In this problem, harbors can be regarded as special depots, and can provide infinite empty containers to other inland depots. In other words, empty or full containers can only be transported or relocated between the three participants. Meanwhile, containers outside the system cannot enter as well. In terms of enterprise, there are only three enterprises in the system, where the one offers transport service of railway (described in detail in the case) and another one is the logistic enterprise that we focus on. The last one is the company that leasing empty containers for logistic enterprise.

- Well-performed containers. Containers are well-performed in the planning horizon, that is, maintenance of containers is not considered in the problem. Thus, transportation of containers only 
aims to finish cargo transport and rebanlance empty containers.

- Type of container. Only one type of container (40-foot container) is employed for cargo transportation,in other words, this is single commodity mode in the case.

- Leasing of empty containers. Rebanlanceing of empty containers in the whole system of an enterprise can be solved by two approaches 1) transporting empty containers owned the enterprise between depots and finally get the balance; 2 ) leasing new empty containers from container leasing company to maintain balanced distribution of empty containers in the system. Transportation enterprise can lease empty containers from container leasing companies with certain leasing costs. A full-developed transportation usually reserves sufficient empty containers near harbors so that it is assumed that harbor can lease empty containers from itself for free, as well as inland depots if transport time permitted. Considering the costs of distant transport, logistic enterprise may lease new containers from other companies to fulfill its gap resulting from the demand of containers.

- Intermediary property of depots. It is assumed that full containers are discharged/unloaded at customers' locations and then returned to depots nearby for a short-time storage, and are ready for the demand of future exporting (demand of empty containers) of customers served by this depot and other depots. Storage costs at depots and harbors are neglected because construction of depots and storage spaces for containers are sunk cost, the cost of storage can be regarded covered by this sunk cost and are not considered in operation costs. If the demand of empty containers from customers can not be satisfied by nearby inland depots, adequate empty containers at harbors will be transferred to inland depots, which is common in real-world operation.

- Two transport modes. Railway and container trucks are treated as the main two ways for container transportation in practice and in our case. Therefore, it is assumed that empty and full containers are transported by railway between depots (harbors are also depots) for long-distance and large-quantity transportation, whereas by container trucks between customers and depots for short-distance and small-quantity transportation.

- Single transport cost. It is assumed there only exists one transport cost between each pair of demand and supply, that is, deterministic transportation costs between two specific locations (customer location and depots).

- Promise and rejection. Once transportation enterprise promises to delivery, then the tasks must be finished. That is, imported containers has already been accepted by logistic enterprise so that these tasks must be finished, whereas some exported containers can be rejected by transportation enterprise because of capacity lacks. Consequently, a rejection usually causes the loss of customer loyalty.

- Capacity. The capacity of depots for storing containers, and the capacity for transporting is infinite.

\subsection{Notations}

To formulate the proposed model for the problem mentioned above, here we first describe the symbols that used in this paper (Table 1).

\subsection{Model}

Transportation/logistic enterprises seek for the maximization of profits in practice, as well as satisfaction of customers. Therefore objective function in the proposed model for inland container transportation problem aims to maximize profits from transporting full containers of customers (inbound and outbound). Meanwhile, penalty costs for rejecting transportation demand of customers are added in the objective for the trade-off between profits and customer satisfaction (service level).

$$
\begin{aligned}
\max P= & \sum_{k} \sum_{n} Y E F_{k n} \times\left(W_{k n}-C Y F_{k n}\right) \\
& -\sum_{m} \sum_{n} C F_{m n} \times E F_{m n}-\sum_{m} \sum_{n} C E_{m n} \times X E_{m n} \\
& -\sum_{n} \sum_{k} C Y E_{k n} \times Y E_{k n}-\sum_{k} \sum_{n} C Y E_{n k} \times Y E_{n k} \\
& -\sum_{n} C Z_{n}-\sum_{m} \sum_{n} C F_{m n} \times I F_{m n} \\
& -\sum_{n} \sum_{k} C Y F_{n k} \times Y E_{n k}-\sum_{k} C G_{k} \times G E F_{k}
\end{aligned}
$$

subject to

$$
\begin{gathered}
\sum_{m \in R} I F_{m i}=\sum_{n \in R} I F_{i n}+\sum_{k \in C} \beta_{k i} \cdot \alpha_{k}, \forall i \in D \\
\sum_{n \in R} E F_{i n}=\sum_{m \in R} E F_{m i}+\sum_{k \in C} \beta_{k i} \cdot\left(b_{k}-G E F_{k}\right), \forall i \in D \\
\sum_{m \in R} I F_{s m}+\sum_{k \in C} \beta_{k s} \cdot \alpha_{k}=\sum_{n \in R} \sum_{k \in C} \beta_{k n} \cdot \alpha_{k}, \forall s \in S \\
\sum_{n \in R} E F_{n s}+\sum_{k \in C} \beta_{k s}\left(b_{k}-G E F_{k}\right)=\sum_{n \in R} \sum k \in C \beta_{k n} \cdot\left(b_{k}-G E F_{k}\right), \forall s \in S
\end{gathered}
$$

$\sum_{k \in C} \beta_{k i} \cdot \alpha_{k}+\sum_{m \in R} X E_{m i}+Z_{i}=\sum_{n \in R} X E_{i n}+\sum_{k \in C} \beta_{k i} \cdot\left(b_{k}-G E F_{k}\right), \forall i \in D$ 
Table 1 Notations for the model

\begin{tabular}{cl}
\hline Parameters of nodes & \\
$S$ & set of harbors, $s \in S$ \\
$R$ & set of inland depots \\
$C$ & set of harbors and inland depots, $R=S \cup D, m, n \in R$ \\
$\beta_{k n}$ & set of customers, $k \in C$ \\
Parameters of costs & 1, if customer $k$ is coverd/served by depot $n ; 0$ \\
$C F_{m n}$ & otherwise. \\
$C E_{m n}$ & unit transportation cost of full container between \\
$C Y F_{k n}$ & unit transportation cost of empty container between \\
& depot $m$ and $n$ \\
$C Y E_{k n}$ & unit transportation cost of full container between \\
$C Z_{n}$ & customer k's location and depot $n$ \\
$C G_{k}$ & unit transportation cost of empty container between \\
& customer $k$ 's location and depot $n$
\end{tabular}

Other parameters

\begin{tabular}{|c|c|}
\hline$a_{k}$ & quantity of import-full containers of customer $k$ \\
\hline$b_{k}$ & quantity of export-full containers of customer $k$ \\
\hline$Y I F_{n k}$ & $\begin{array}{l}\text { quantity of full containers for import from depot } n \text { to } \\
\text { customer k's location }\end{array}$ \\
\hline$Y E F_{k n}$ & $\begin{array}{l}\text { quantity of full containers for export from customer } \\
k^{\prime} \text { s location to depot } n\end{array}$ \\
\hline$Y E_{n k}$ & $\begin{array}{l}\text { quantity of empty containers from depot } n \text { to } \\
\text { customer } k^{\prime} \text { 's location }\end{array}$ \\
\hline$Y E_{k n}$ & $\begin{array}{l}\text { quantity of empty containers from customer k's } \\
\text { location to depot } n\end{array}$ \\
\hline$W_{k n}$ & unit revenue for transporting customer k's full \\
\hline
\end{tabular}

decision variables

IF $\quad$ quantity of import-full containers that transported from depot $m$ to depot $n$

$E F_{m n} \quad$ quantity of export-full containers that transported from depot $m$ to depot $n$

$X E_{m n} \quad$ quantity of empty containers that transported from depot $m$ to depot $n$

GEF $\quad$ quantity of customer k's abandoned demand for empty container by transportation enterprise

$Z_{n} \quad$ quantity of empty containers leasing at depot $n$

$S E_{S} \quad$ quantity of empty containers leasing at harbor $s$

$\sum_{k \in C} \beta_{k s} \cdot \alpha_{k}+\sum_{m \in R} X E_{m s}+S E_{s}=\sum_{n \in R} X E_{s n}+\sum_{k \in C} \beta_{k s} \cdot\left(b_{k}-G E F_{k}\right), \forall s \in S$

$X E_{m n} \cdot X E_{n m}=0, \forall m, n \in R$

$$
Y I F_{n k}=\beta_{k n} \cdot \alpha_{k}, \forall n \in R, \forall k \in C
$$

$$
Y E F_{k n}=\beta_{k n} \cdot\left(b_{k}-G E F_{k}\right), \forall n \in R, \forall k \in C
$$

$Y E_{k n}=\left\{\begin{array}{r}\beta_{k n} \cdot \alpha_{k}-\beta_{k n} \cdot\left(b_{k}-G E F_{k}\right), \beta_{k n} \cdot \alpha_{k}-\beta_{k n} \cdot\left(b_{k}-G E F_{k}\right)>0 \\ 0, \beta_{k n} \cdot \alpha_{k}-\beta_{k n} \cdot\left(b_{k}-G E F_{k}\right) \leq 0\end{array}\right.$

$$
Y E_{n k}=\left\{\begin{array}{r}
\beta_{n k} \cdot\left(b_{k}-G E F_{k}\right)-\beta_{n k} \cdot \alpha_{k}, \beta_{n k} \cdot\left(b_{k}-G E F_{k}\right)-\beta_{n k} \cdot \alpha_{k}>0 \\
0, \beta_{n k} \cdot\left(b_{k}-G E F_{k}\right)-\beta_{n k} \cdot \alpha_{k} \leq 0
\end{array}\right.
$$

$$
I F_{m n}, E F_{m n}, X E_{m n}, G E F_{k}, Z_{i} \geq 0, \text { and } \in \text { integer }
$$

$$
S E_{s} \in \text { integer }
$$

The revenue in the objective function represents the income of carrying exported full containers, and the costs are transportation costs of exported full containers between depots and customers, transportation costs of exported full and empty containers between depots, transportation costs of empty containers between depots and customers, penalty costs of abandoned containers (rejected demand by transportation enterprise), transportation costs of leasing empty containers, transportation costs of full-imported containers between depots, and transportation costs of full-imported containers between nodes and customers.

Equations 2 and 3 are the flow conservations of full imported containers and full exported containers at depot $i$, while Eqs. 4 and 5 are the flow conservations of imported and exported full containers at harbor $s$. Equation 6 is the flow conservation of imported and exported empty containers at inland depot $i$. Equation 7 is the constraint of empty containers flow conservation at harbor $s$. That is, the sum of empty containers dispatched from harbor to inland depots and exported full containers, equals to the sum of full-imported containers in the research region, empty containers from inland depots to harbor and empty containers that leased at harbor. Equation 8 is the constraint of empty containers flow of transportation network, which means the flow direction of empty containers can only be one direction and no reverse direction. Equations $9-12$ are the settings of transportation volume. Equations 13 and 14 are the constraints of variables. The proposed integer model is programmed in IBM CPLEX Optimizer with integer programming solver. 


\section{Case study}

The transportation network in the northeast of China is selected as the case to evaluate the performance of the proposed model, and as the main transfer port in the Bohai Bay area, Dalian port is the transportation hub of the three provinces in this region. In the northeast China, almost $90 \%$ of the container transportation is transferred through Dalian Port. After unloading at Dalian port, full containers will be transported by railway to each depot that the transportation enterprise owns, with the longest inland-haul of $1925 \mathrm{~km}$. Benefiting from the high ratio and large quantity of container transportation, the transportation enterprises in this area gradually build up their transportation networks. After years of development, intermodal transport has become increasingly mature via Dalian port, as well as the railway-truck combined transport system. 14 lines of container trains through Shenyang, Changchun, Jilin, Wushu, Harbin and Daqing have been opened with the five-fixed concept: fixed schedule, station, route, price, and trains fleet. A complete railway network is possible for the logistic enterprise to offer transportation service through railway in the northeast China. Meanwhile, logistic enterprises such as China Ocean Shipping Company and Sinotrans operate similar intermodal transportation of container in this region. Logistic enterprise faces up with the repositioning problem of empty containers and delivery of full containers at the same time. Hence, this paper chooses Dalian port and its northeast hinterland as the research region and the real transportation network of the container transportation enterprise (see Fig. 1) to evaluate the proposed model and algorithm, which is meaningful for logistic enterprise to optimize its service, network and operation.

There are one harbor (Dalian) and ten inland cities (Shenyang, Tongliao, Changchun, Jilin, Yanji, Manzhouli, Qiqihaer, Daqing, Harbin and Suifenhe) in this region, as shown in Figs. 2 and 3. The logistic enterprise has one depot at each inland city as well as harbor, for container delivery and collection. The transportation distances between depots in the transportation network are shown in Table 4 in Appendix.

\subsection{Data collection}

\subsubsection{Planning horizon and transportation demand}

According to the practical operation, one week is set as the planning horizon in this paper because container lines are regularly visit a port in frequency of one week. Hence, containers are normally collected or delivered in a week. That is, the quantity of inbound and outbound containers

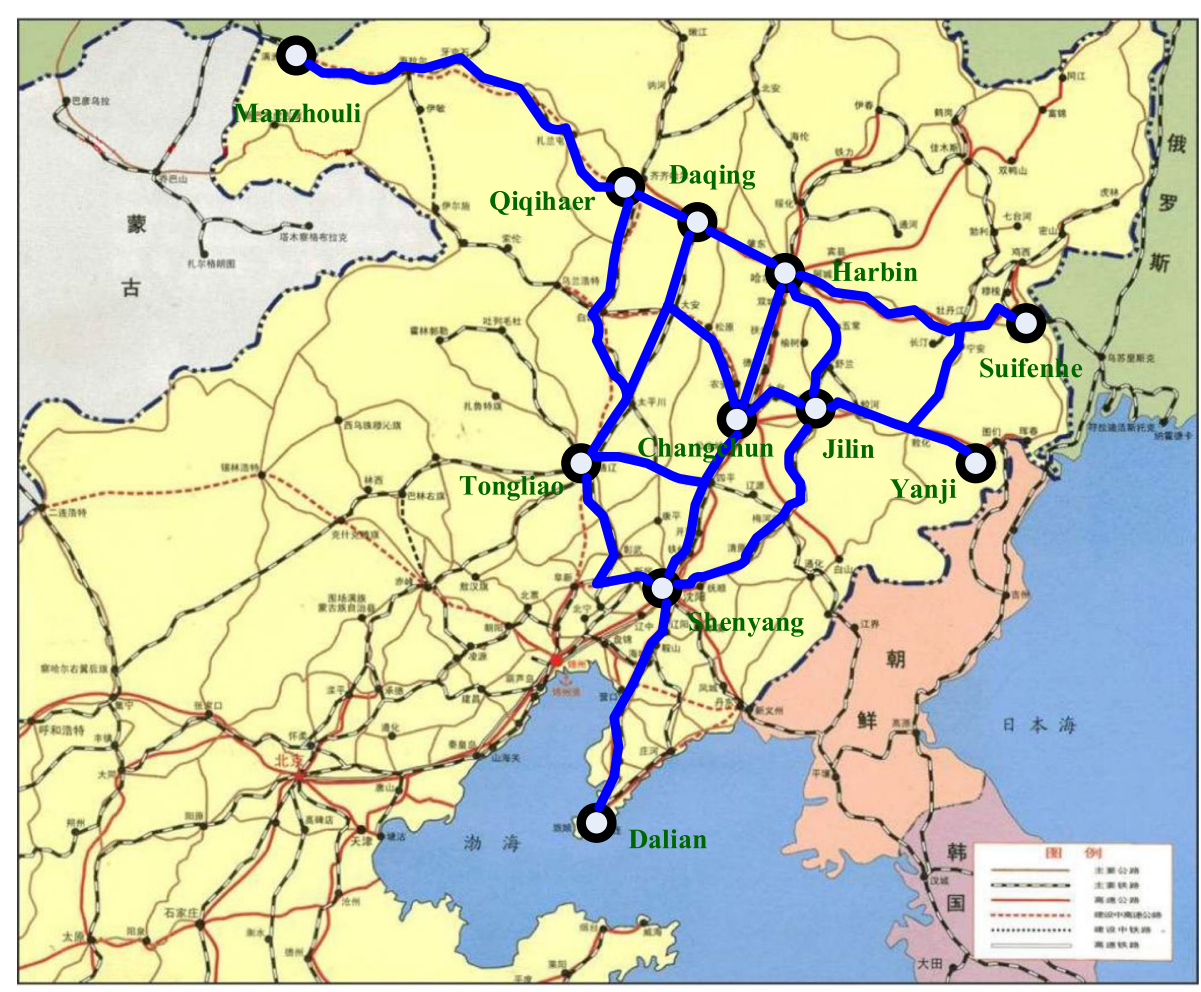

Fig. 2 Real transportation network of a transportation enterprise in Northeast China 


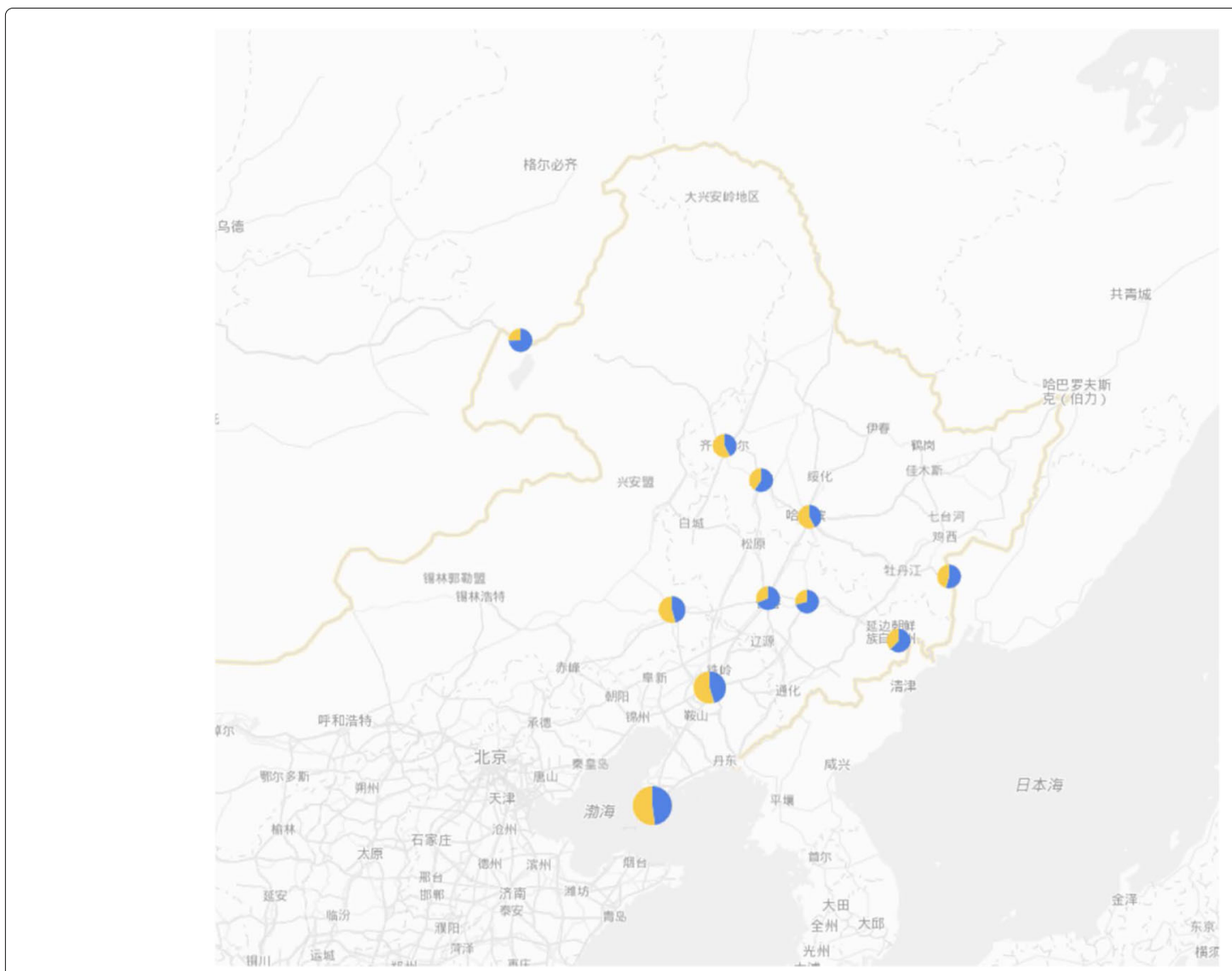

Fig. 3 Quantity of import and export containers. Yellow: export; Blue: import; Size: quantity

is set as the value during one week for the planning horizon from current available data. Table 2 is the quantity of full containers (imported and exported full containers), in other words, demand of transportation. Note that part of the full containers will convert to empty containers dynamically after discharging and this issue is also considered in the case. Imported containers are the containers that must (see Assumptions) be transported by the logistic enterprise, while not all exported containers are promised to be transported to the harbor (Dalian port) for the up-coming sea-going transportation.

\subsubsection{Revenue of transportation}

As described in the model, this paper aims to maximize profits of the container transportation enterprise and imported containers must be delivered so that the profits are calculated based on the revenues for carrying exported containers, rather than imported containers (because the revenue of transporting imported containers is fixed). In order to simplify the calculation and make it easy when analyze, incomes of transporting full-exported containers from each inland depot are considered consistent, and the income can be obtained by inquiring the quotation on the
Table 2 Quantity of import-containers and export-containers of each depot, unit revenue of transporting export-container from each depot to harbor, penalty cost of abandoned demand of customers at each depot

\begin{tabular}{lllll}
\hline Depot & $\begin{array}{l}\text { Qol } \\
\text { [container] }\end{array}$ & $\begin{array}{l}\text { QoE } \\
\text { [container] }\end{array}$ & $\begin{array}{l}\text { Revenue [Yuan/ } \\
\text { container] }\end{array}$ & $\begin{array}{l}\text { Penalty cost } \\
\text { [Yuan/container] }\end{array}$ \\
\hline Dalian & 3132 & 3404 & 2300 & 4600 \\
Shenyang & 1545 & 1865 & 3000 & 3570 \\
Changchun & 356 & 163 & 4500 & 4448 \\
Yanji & 41 & 25 & 6200 & 5138 \\
Jilin & 118 & 49 & 5600 & 6180 \\
Harbin & 298 & 407 & 6400 & 6362 \\
Daqing & 145 & 99 & 6000 & 5106 \\
Qiqihaer & 157 & 214 & 6300 & 5284 \\
Suifenhe & 206 & 172 & 4750 & 50 \\
Tongliao & 981 & 1175 & 5200 & 5860 \\
Manzhouli & 43 & 14 & 7500 & 4078 \\
\hline
\end{tabular}


official website of the transportation enterprise, as shown in Table 2. Note that the revenue stands for the sale price of the transportation from depots to harbor.

\subsubsection{Transportation costs of railway}

An economical choice for transportation/logistic enterprise is to transport containers by railway for long haul movements, which is more environmental and economical if compared with container trucks. Therefore, operators of container transportation commonly seek help from railways, especially in long haul transportation between depots. Railway transportation for containers in China is monopolized by China Railway, a state-owned company, and the transportation costs are calculated as Eq. 15. Here the discount for large volume of container transportation between logistic enterprise and China Railway is not considered.

$$
C=\left(C_{0}+f \cdot D\right) \cdot n
$$

where $C$ stands for transportation cost, $C_{0}$ represents basic cost (lowest price). $f$ is the unit cost of transporting a 40-foot container, $D$ stands for the distance and $n$ stands for numbers of containers. $C_{0}$ and $D$ are set as 459 yuan per container and 1.904 yuan/(kilometer - container) by the freight rate of China Railway.

Transportation cost of empty containers are set as $40 \%$ of that of full containers and specific costs between depots are listed in Appendix Table 5 and 6.

\subsubsection{Penalty cost of abandoned demand}

Owing to the gap between quantity of owned containers and customers' demand for empty containers at each depot, it is possible that transportation enterprise may abandon/reject part of customers' demand because of the shortage of empty containers. However, the rejection will cause the decrease of customer loyalty, future operation profits and customer satisfaction. On one hand, rejection of a customer's demand contributes to the loss of potential orders (demand for transporting) by the decrease of loyalty in the future. On the other hand, rejection in the planning horizon will result in an immediate loss of profits for transporting the abandoned demand. Hence, penalty cost, is incorporated in the objective function to maintain the service level of the transporting enterprise, which involves two parts.

The first part is the loss of demand in the following planning horizon because transportation enterprise cancels the shipment in the current planning horizon. The second part is the opportunity cost of transporting the abandoned containers, which can be calculated by the revenue minus the transportation cost from inland depots to Dalian port. The loss of future and current profits are set the same and the sum of the two parts are penalty costs of rejecting unit transportation demand (one container) at each depot (Eq. 16), as shown in Table 2. The penalty costs at different depots differ from each other since the values of transportation service at each depot are different. Penalty cost is set based on the value of transportation service that offered by logistic enterprise.

$$
C G_{k}=2 \cdot G E F_{k} \cdot \sum_{n}\left(W_{k n}-C Y F_{k n}\right)
$$

\subsubsection{Container transportation of container trucks}

In terms of short-haul transportation between customer' locations and depots, container trucks are a relatively good choice for its convenience. In the real case, two or three typical customers with largest transportation demands (imports or exports) that served by each depot are selected, that is, 27 customers in total. The distances from each customer's location to the corresponding depot are listed in Appendix Table 7. The quantity of full-imported containers and full-exported containers is shown in Table 3.

Generally, there exists two types of transportation by trucks, that is, 1) delivery and collection of full containers, and 2) delivery and collection of empty containers. Freight rate for transporting full containers is 9 Yuan/(container . $\mathrm{km}$ ), and that of empty container is 5.4 Yuan/(container . $\mathrm{km})$, see Appendix Table 7.

Full-imported containers will be transported from depots to customer's locations by trucks, and then the containers will be returned to depots nearby once discharged. Note that after this operation, full containers convert to empty ones. If customers have cargos to export which needs empty containers as the tank, depots of the transportation enterprise will then supply empty containers to customers. After charging, the containers (full

Table 3 Quantity of import-containers and export-containers of each customer

\begin{tabular}{llllll}
\hline Cus No. & QIC & QEC & Cus No. & QIC & QEC \\
\hline 1 & 1359 & 0 & 15 & 184 & 143 \\
2 & 1773 & 1854 & 16 & 0 & 264 \\
3 & 0 & 1550 & 17 & 145 & 49 \\
4 & 640 & 0 & 18 & 0 & 50 \\
5 & 905 & 1150 & 19 & 85 & 131 \\
6 & 0 & 715 & 20 & 72 & 83 \\
7 & 135 & 0 & 21 & 100 & 0 \\
8 & 221 & 85 & 22 & 106 & 172 \\
9 & 0 & 78 & 23 & 355 & 0 \\
10 & 15 & 25 & 24 & 626 & 590 \\
11 & 26 & 0 & 25 & 0 & 585 \\
12 & 54 & 25 & 26 & 43 & 0 \\
13 & 64 & 24 & 27 & 0 & 14 \\
14 & 114 & 0 & & & \\
\hline
\end{tabular}




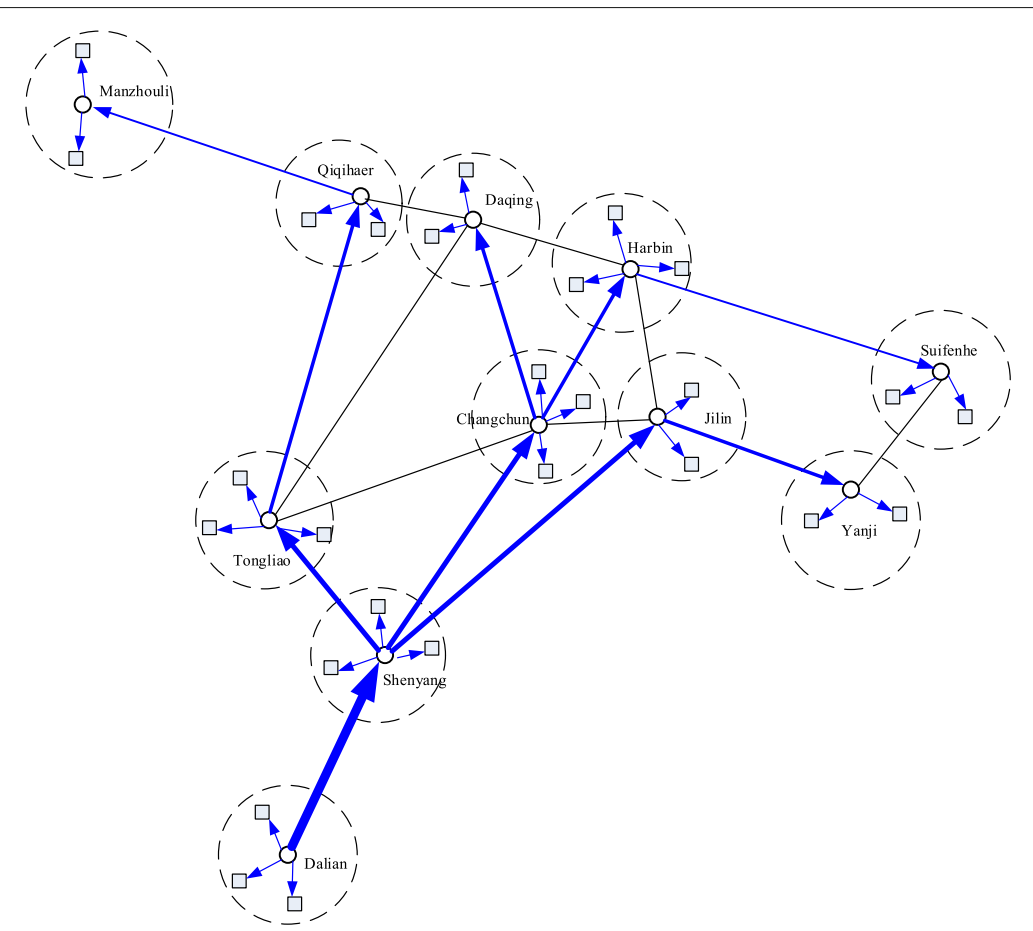

Fig. 4 Transportation of import-full containers

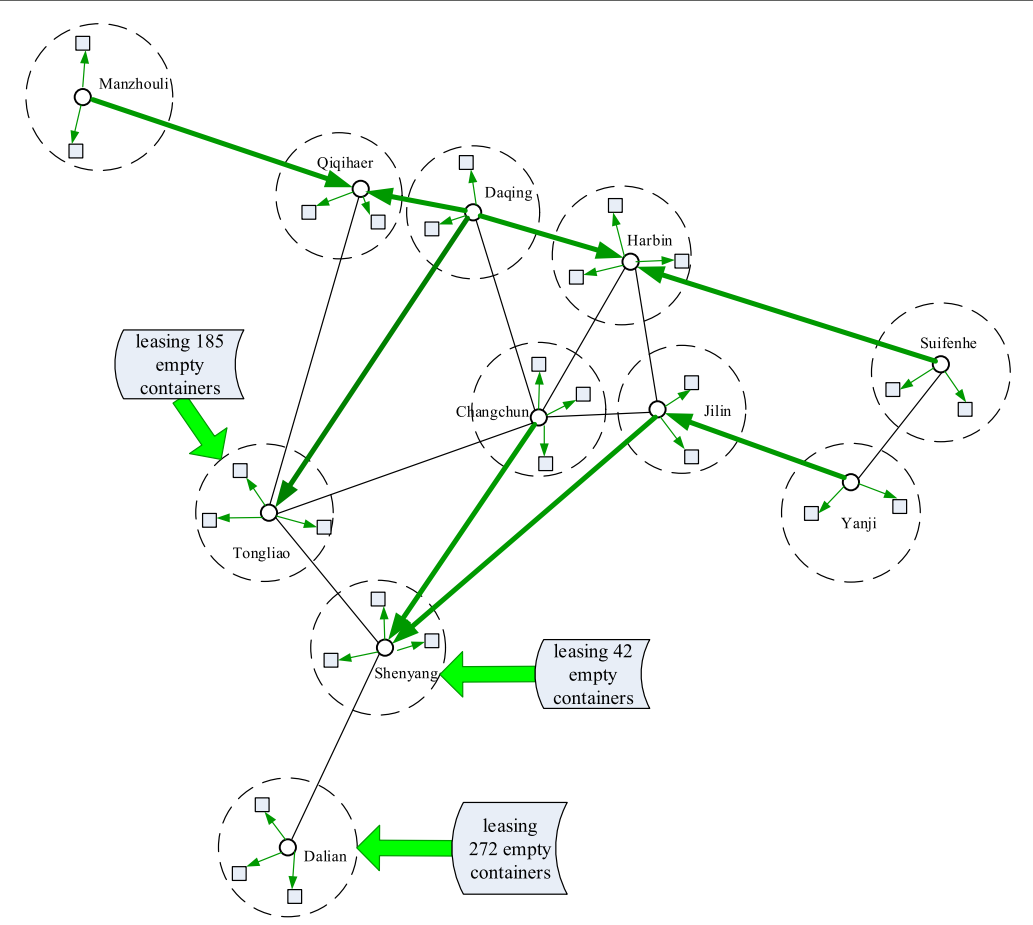

Fig. 5 Transporting and leasing of empty containers 


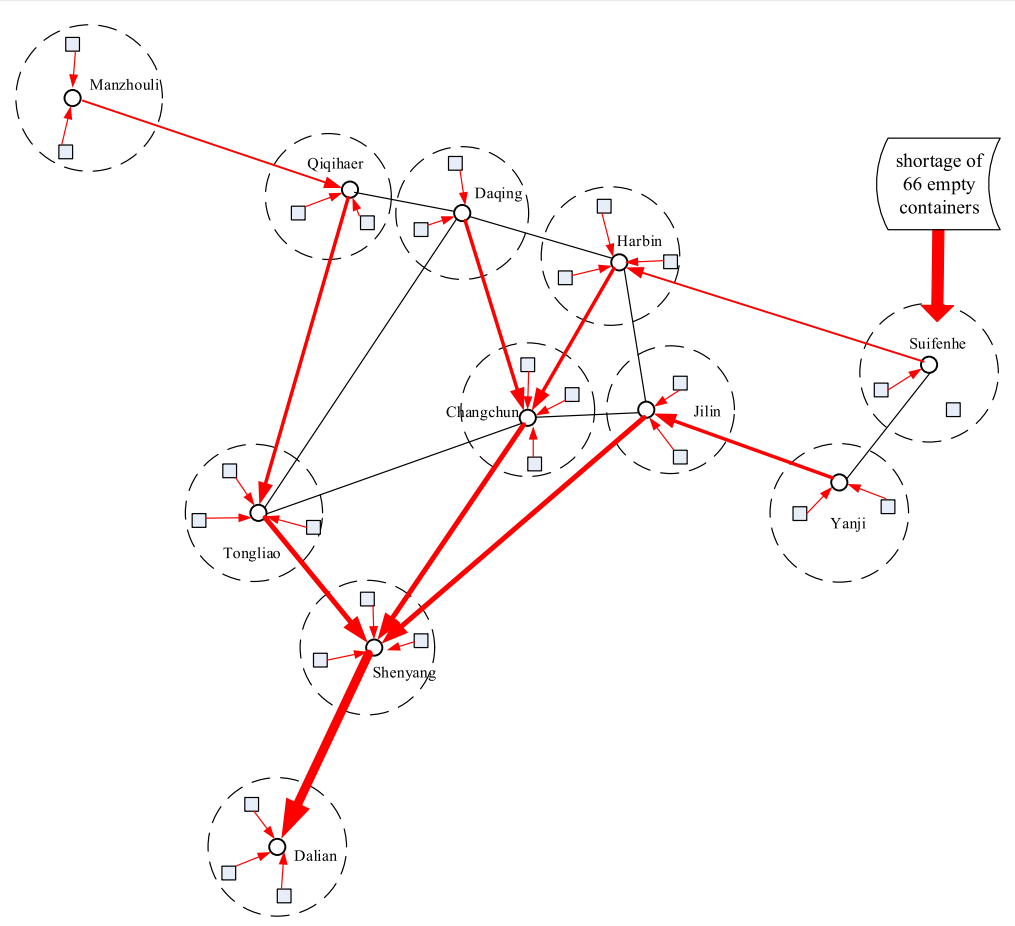

Fig. 6 Transportation of export-full containers and abandoned demand

container) will be shipped to Dalian port via trucks and trains.

Two choices exist for the transportation enterprise if there is no more empty containers at certain depots to provide to customers. First, the enterprise can dispatch surplus empty containers from other depots owing to the imbalance of imports and exports transportation. Second, leasing empty containers with the limitation of time span (e.g. at least one month) from other transportation enterprises. Leasing an empty container is set as 25 Yuan/day
(750 Yuan for one month), and leasing time span is set to one month. In summary, the transportation enterprise can choose to 1) dispatch self-owned empty containers from other depots, 2) lease from other enterprises or 3) abandon corresponding transportation demand, considering the profits of each choice. Note that as the harbor city in the case, Dalian is regarded as the hub of the transportation network, where self-owned empty containers are assumed to be infinite as mentioned in Assumptions. In other words, it is free to lease empty containers from

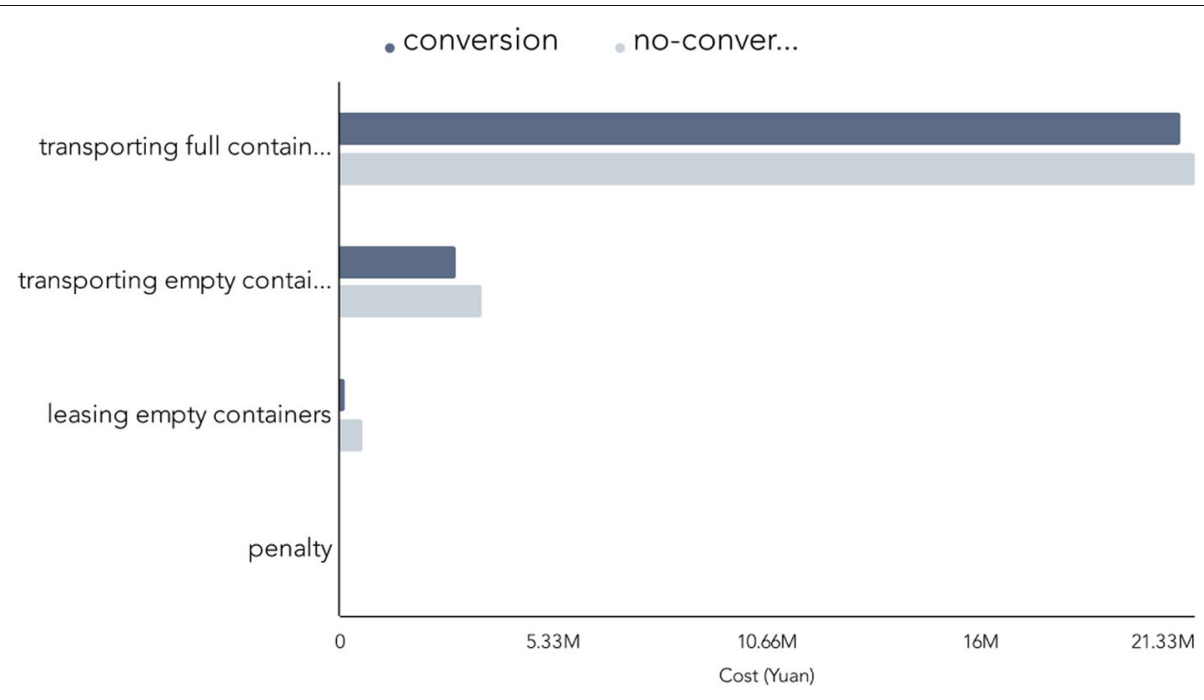

Fig. 7 Operating costs whether consider conversion of containers or not 


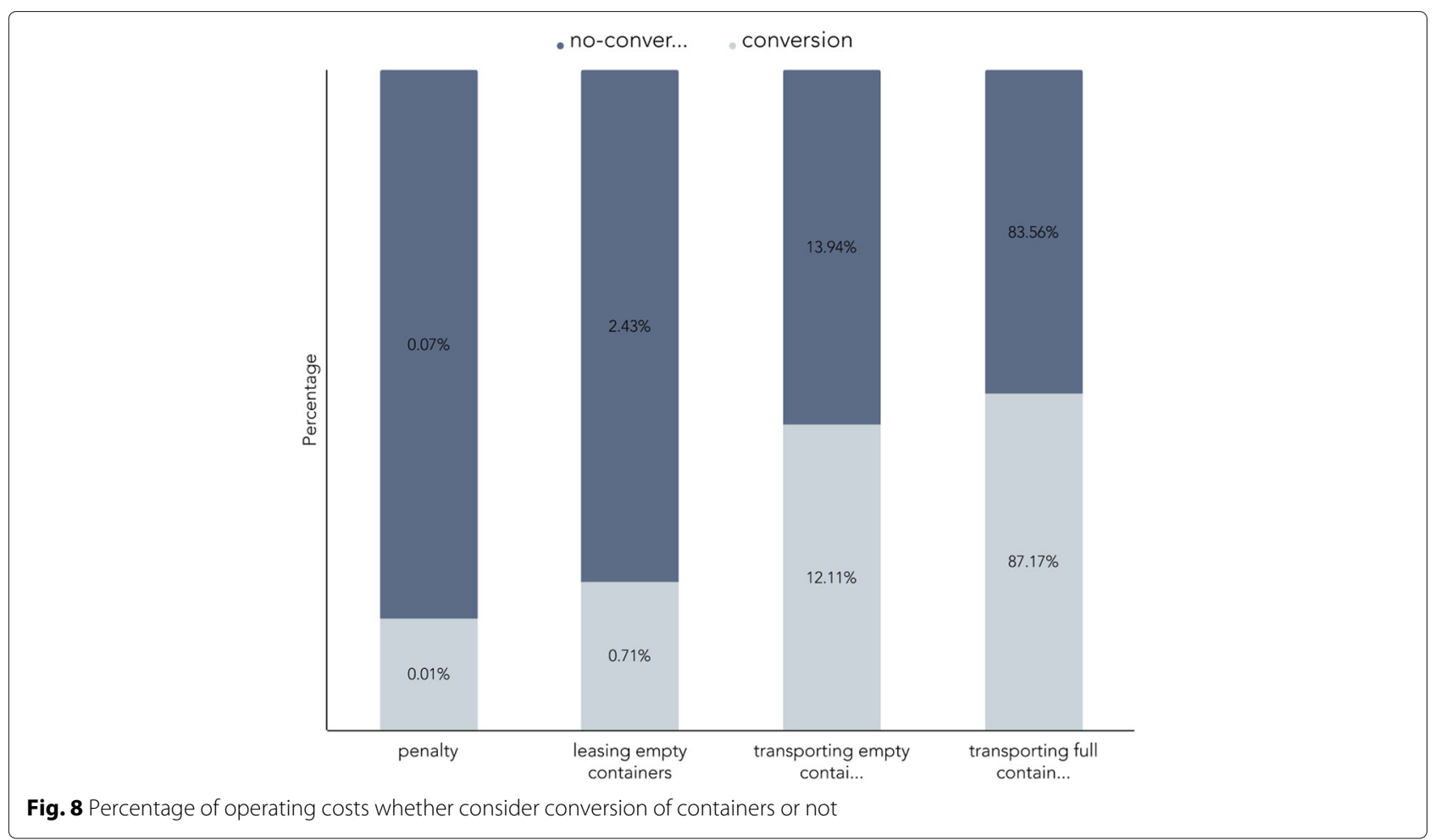

Dalian depot, but the transport costs of these leasing containers should be taken into account in operations.

\subsection{Computational results}

The transportation of full-imported containers in Northeast China is illustrated in Fig. 4, where containers are mainly transported via inland depots of Shenyang, Tongliao and Changchun. The three depots play the role of subregional hubs because of the large quantity of imported-containers and better geographical locations in the transportation system.

Repositioning of the self-owned empty containers of the transportation enterprise is common and the leasing of empty containers happens in three large depots. In Fig. 5, repositioning and leasing of empty containers are illustrated. In Manzhouli, Daqing, Suifenhe, Yanji, Jilin and Changchun, containers that discharged at import-customers' locations are not transported to harbor

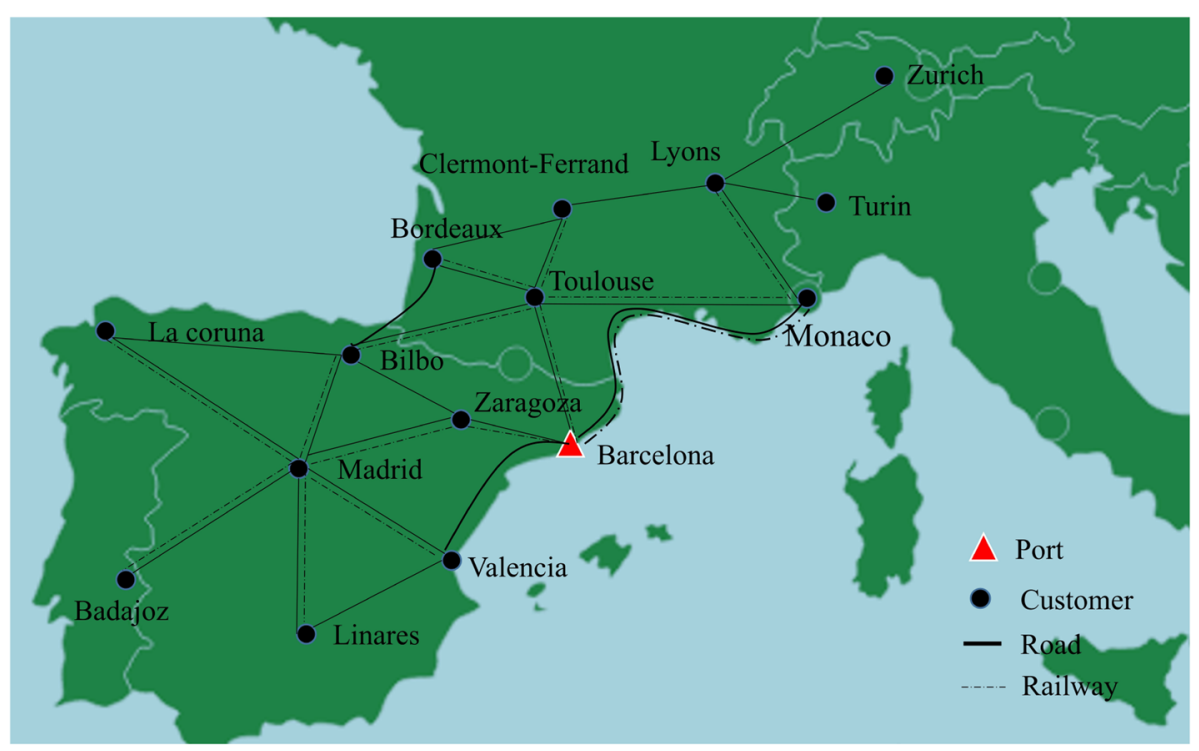

Fig. 9 Real transportation network of a transportation enterprise in part of southern Europe 


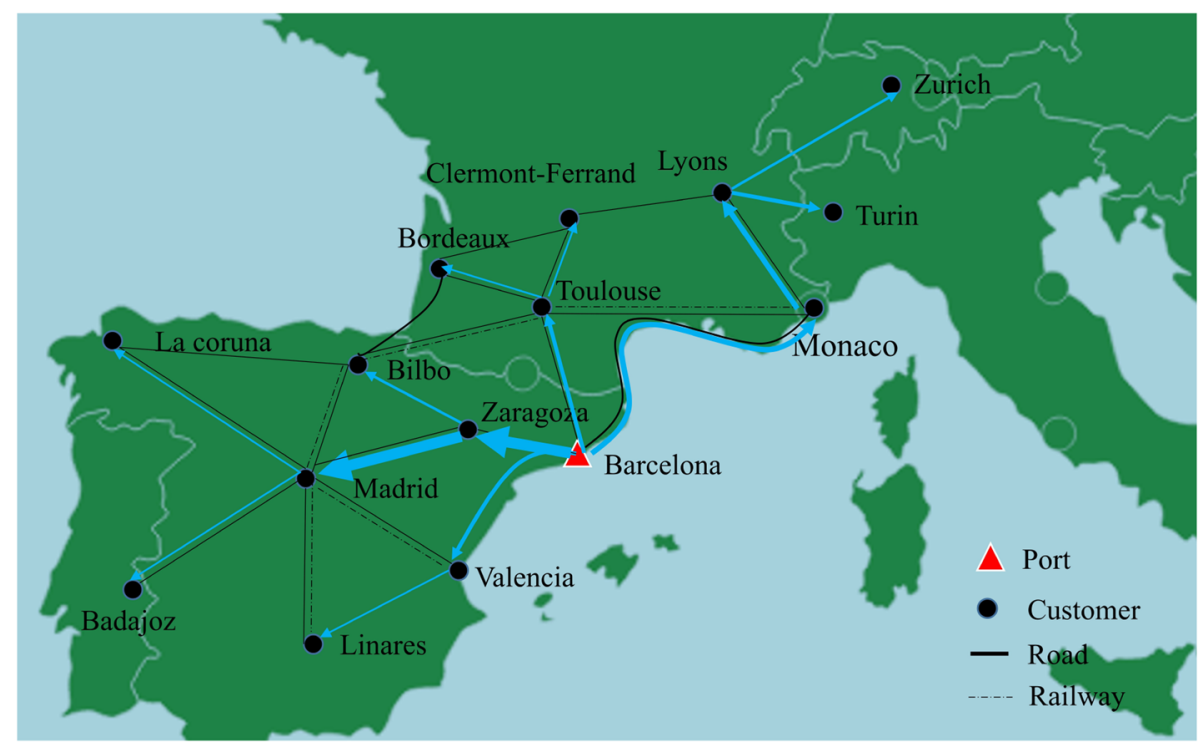

Fig. 10 Transportation of import-full containers

(Dalian) since this paper considers the conversion of containers. That is, full containers will convert to empty containers after discharging. Therefore, the inland depots collect the empty containers for the demand of exporting that they serve. Surplus empty containers are dispatched between depots owing to the gaps between the quantities of imports and exports, mostly adjacent depots, e.g., from Changchun to Shenyang.

In Tongliao and Shenyang, the two inland depots have large demands for empty containers because of the larger export demands. Apart from the supports from other inland depots (Jilin, Changchun and Daqing), the two depots still need to lease empty containers (185 at
Tongliao and 42 at Shenyang) from other transportation enterprises because the transportation costs of empty containers from distant depots is not economical enough than leasing. In other words, higher dispatching costs than leasing costs. Dalian, as a harbor city and a much more developed city with larger imports and exports, leases 272 empty containers for free, according to the assumptions, to supplement the gap between imports and exports. Note that although Dalian can lease containers for free, Tongliao and Shenyang still choose to lease from other enterprises because higher transportation costs between Dalian and themselves, that is, a slow remedy cannot meet an emergency. The cooperation with China Railway may

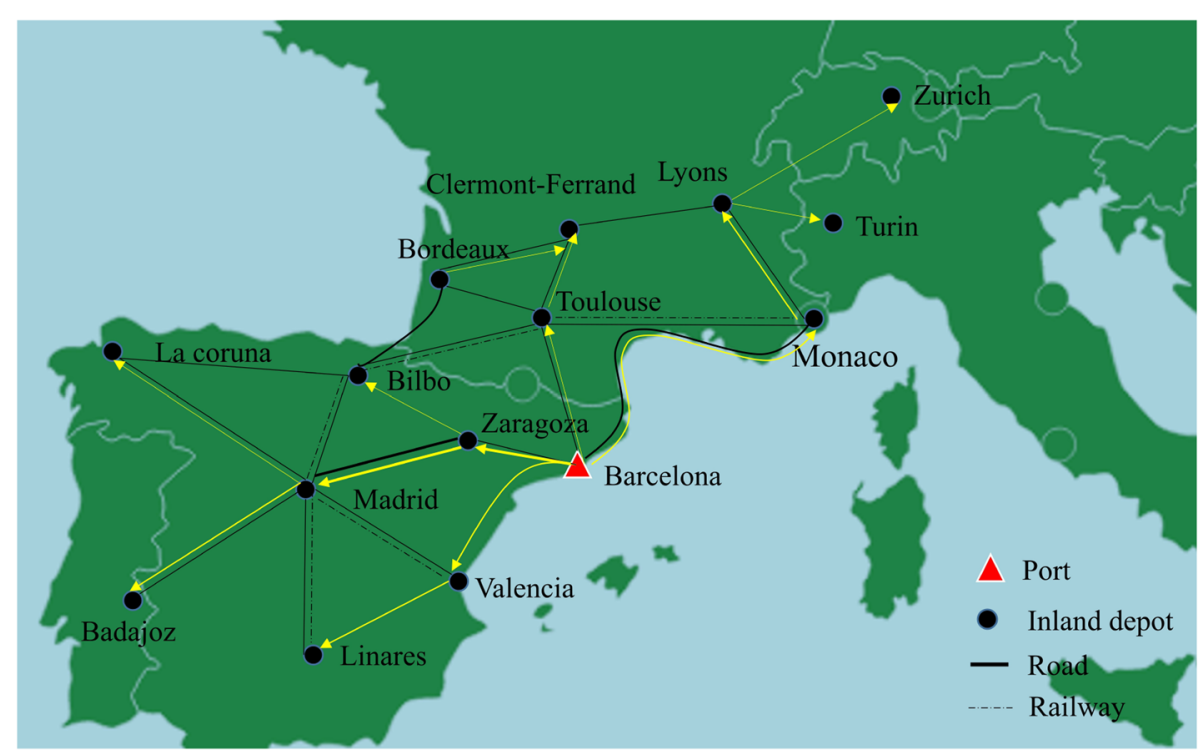

Fig. 11 Transportation of empty containers 


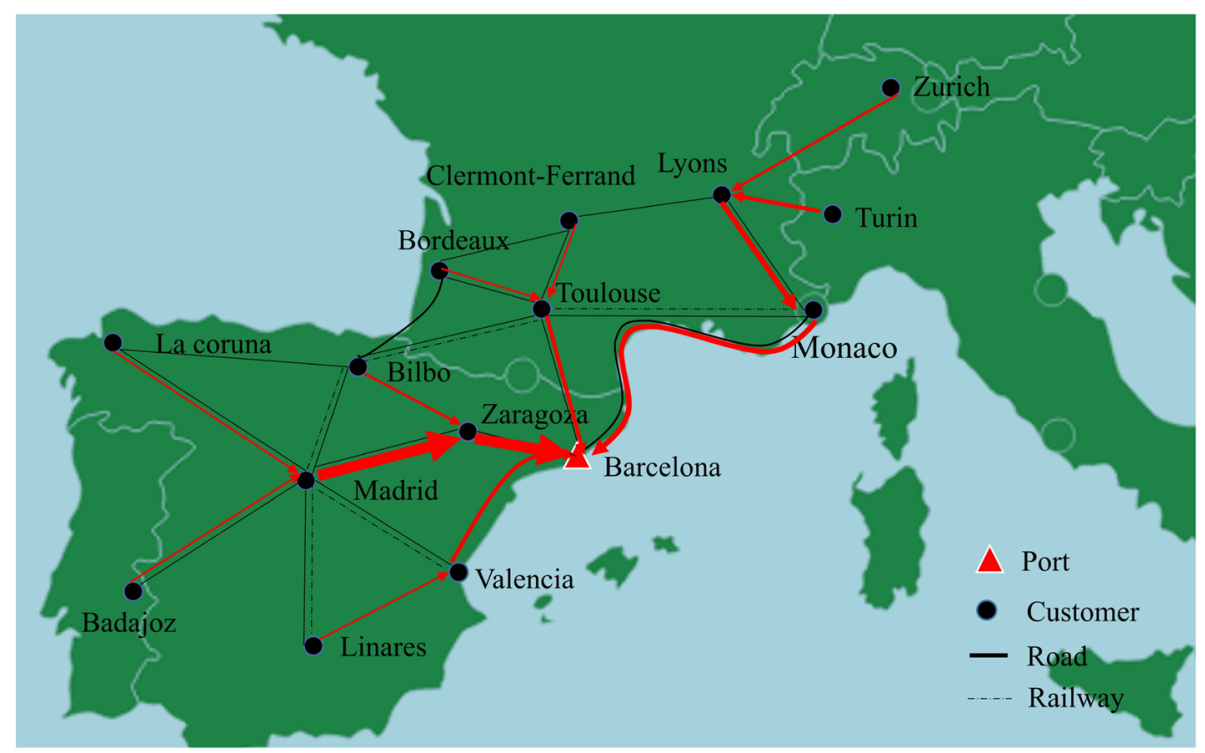

Fig. 12 Transportation of export-full containers

lower down the costs of dispatching empty containers, which will result in fewer leasing containers from other enterprises. Meanwhile, an alternative choice is to cooperates with competitors, e.g., alliance in leasing empty containers.

After dispatching, export customers may have enough empty containers to fill exported cargos into containers and then send to consignees. The results of transporting full-exported containers are shown in Fig. 6. Only 66 over 7587 outbound containers are abandoned by the transportation enterprise. It can be seen that transportation path of customer's exported containers is basically the same as that of customer's imported full containers. In Suifenhe, the container transportation enterprise abandons the demand of 66 containers due to the lower incomes at this region and the lower penalty costs. Back to the dispatching of empty containers between Suifenhe and Harbin, it is found that 100 empty containers are transferred from Suifenhe to Harbin because of the higher unit profit for transporting exported containers at Harbin. Therefore, 66 over 172 outbound demands are abandoned in Suifenhe. If the operators of the transportation enterprise pay more attention on customer's satisfaction (service level), then the penalty costs in the model will increase to fit operators' preferences to make the proposed model feasible.

In summary, the total transportation cost is summed as 23,936 thousand CNY, in which repositioning of empty containers costs 2920 thousand $\mathrm{CNY}$ and the cost of transporting full containers is 21,016 thousand CNY. Owing to the gap between imports and exports, the enterprise leases 272 free empty containers from itself at Dalian port, and rental costs paid to other enterprises are 170 thousand CNY to satisfy export-customers' demand for empty containers. But not all demand of customers are satisfied, 66 demand for containers are abandoned which costs $3300 \mathrm{CNY}$.

Because the planning horizon is set as one week in the case study, and the capacity of depots during one week is vague, this paper takes number of turnover containers that each depot can handle in a week as the capacity. Actually, each depot in China has a designed turnover capacity before constructing and these capacities are usually designed at least five years in advance, which means the capacity of depots can cover the estimated demand of containers storage five years later. Therefore, capacity of depots is assumed to be infinite in Assumptions because of the large buffer of capacity in advance.

\subsection{Comparison}

The proposed model considers the transportation of full and empty containers together, i.e., the conversion of containers, we design a comparison of the results artificially which do not consider the conversion of containers. If we do not consider the conversion of containers in terms of full or empty status, it means that after discharging of full containers, the containers will not be further used for outbound cargos, or in other words, they will not be considered in the transportation anymore.

It can be seen that the total transportation costs of empty containers if consider conversion of containers is lower than that if conversion is not taken into account (Figs. 7 and 8). Meanwhile, costs of transporting empty containers, leasing empty containers from container leasing enterprises and the penalty costs for abandoned demands are all larger and occupy larger percentage than 
that if we consider conversion. For container logistic enterprises, considering the conversion of containers and hence decreasing the dispatching of empty containers can significantly reduce total transportation costs. In detail, considering the conversion saves 689 thousand CNY in transportation costs of empty containers, 312 thousand for full containers, and gets 1.1 billion CNY cost more than that of not considering.

There exists a shortage of approximately 550 empty containers in the selected region monthly. That is, the transportation enterprise needs to replenish this shortage by dispatching containers outside the region or renting from container leasing enterprises in the long term. Since the time horizon is set as one week and operations of transportation is organized weekly considering real-world operations of container lines (arrive at the same port per week). In this case, all transportation can be satisfied considering the real railway schedules for container cargos.

It is also interesting to reveal the equity among different depots, although the results are feasible and can increase profits of the logistic enterprise. In practice, logistic enterprise operates for chasing more profits, and specific operations are usually in the charge of individual operator at different depots. The decisions of the enterprise, however, might injure profits of individual depots for the sake of total profits, e.g., Suifenhe (see Fig. 6). In detail, depot Suifenhe abandons 66 demand for exporting and endures corresponding penalty costs for the sake of the total benefits of the enterprise. It is apparently unfair for Suifenhe because its empty containers are transported to Harbin even it has a lack in empty containers as well. It is also reasonable economically owing to the much lower penalty costs for abandoning demands at Suifenhe (50 CNY). The result reveals the poor pricing policy at Suifenhe due to the governed maximum freight rate, which is not reasonable economically in the long term, which will deteriorate the exports environment apparently by the hands of benefit-chasing transportation enterprise.

\subsection{An application for European harbor-inland regions}

In this sector, port of Barcelona and its hinterlands shown by Fig. 9 are taken as research objects. The related data is obtained from [14]. The transportation of full and empty containers is shown by Figs. 10, 11 and 12. The total transportation cost is 1306 thousand EUR, in which repositioning of empty containers costs 56.8 thousand EUR. It can be seen that Madrid, Toulouse and Monaco are transfer nodes because of the large container flows. Owing to the gap between imports and exports in the hinterlands of Barcelona, empty containers should be repositioned from port of Barcelona to the hinterlands. Thus, it is beneficial to establish large depots in Madrid, Toulouse and Monaco to store empty containers temporarily. The cost of repositioning empty containers could be reduced as the distance of repositioning empty containers decreases. In additional, it brings the advantage of economies of scale if full of containers are transported to the depots and then dispatched to customers. Accordingly, the cost of transporting full containers is reduced. The revenue of the transportation enterprise increases.

\section{Conclusions}

Considering the conversion of containers in transportation, this paper proposes an optimization model for the intermodal transportation of full and empty containers in hinterlands. Different from cost minimization in the literature, this paper models the transportation problem based on revenue management. The model aims to maximize profits of transportation enterprise with specific constraints in container transportation. Since transportation enterprises aim for profit-maximization, it is permitted that transportation demands from customers can be rejected in an overall consideration, which is reasonable and common in real-world case.

A real case of the transportation networks in Northeast China is used to evaluate the proposed model, and analysis shows that the total profits can be enlarged by considering the conversion of containers during transportation. Therefore, transportation enterprise can gather the discharged containers in time from import customers for the further use of outbound cargos. In addition, it can verify that the optimization of inland transportation of empty and full containers can reduce the operating costs of logistic enterprises. Additionally, results uncover the fact that a governed pricing policy at Suifenhe is not reasonable and may deteriorate the future export environment inferring from the rejected transportation demands there. From the real transportation network of a transportation enterprise in part of southern Europe, it can be seen that establishing inland depots could bring the advantage of economies of scale. The costs of transporting empty and full containers can be reduced. It seems that the port, customer, inland transport operator and possibly container shipping company in Europe may benefit.

There are several possibilities for future research. Time horizon of planning/operation can be more subdivided, in other words, time window can be considered in the optimization problem (e.g., VRP of container trucks, schedule of trains between depots). In addition, transportation of containers which originates and ends at the observed region can also be integrated with the transportation of containers for international trades, that is, both of international and regional containers are operated together in practice.

\section{Appendix}


Table 4 Distance matrix of the network $(\mathrm{km})$

\begin{tabular}{llllllllllll}
\hline & Dalian & Shenyang & Changchun & Yanji & Jilin & Harbin & Daqing & Qiqihaer & Suifenhe & Tongliao & Manzhouli \\
\hline Dalian & 0 & 397 & - & - & - & - & - & - & - & - & - \\
Shenyang & 397 & 0 & 303 & - & 438 & - & - & - & - & 316 & - \\
Changchun & - & 303 & 0 & - & 128 & 254 & 374 & - & - & 322 & - \\
Yanji & - & - & - & 0 & 349 & - & - & - & 493 & - & - \\
Jilin & - & 438 & 128 & 349 & 0 & 279 & - & - & - & - & - \\
Harbin & - & - & 254 & - & 279 & 0 & 196 & - & 563 & - \\
Daqing & - & - & 374 & - & - & 196 & 0 & 145 & - & 432 & - \\
Qiqihaer & - & - & - & - & - & - & 145 & 0 & - & 488 & -706 \\
Suifenhe & - & - & - & 493 & - & 563 & - & - & 0 & - & - \\
Tongliao & - & 316 & 322 & - & - & - & 432 & 488 & - & 0 & - \\
Manzhouli & - & - & - & - & - & - & - & 706 & - & - \\
\hline
\end{tabular}

Table 5 Unit cost of a heavy container in railway transport (CNY)

\begin{tabular}{|c|c|c|c|c|c|c|c|c|c|c|c|}
\hline & Dalian & Shenyang & Changchun & Yanji & Jilin & Harbin & Daqing & Qiqihaer & Suifenhe & Tongliao & Manzhouli \\
\hline Dalian & 0 & 1215 & - & - & - & - & - & - & - & - & - \\
\hline Shenyang & 1215 & 0 & 1036 & - & 1293 & - & - & - & - & 1061 & - \\
\hline Changchun & - & 1036 & 0 & - & 703 & 943 & 1171 & - & - & 1072 & - \\
\hline Yanji & - & - & - & 0 & 1123 & - & - & - & 1398 & - & - \\
\hline Jilin & - & 1293 & 703 & 1123 & 0 & 990 & - & - & - & - & - \\
\hline Harbin & - & - & 943 & - & 990 & 0 & 832 & - & 1531 & - & - \\
\hline Daqing & - & - & 1171 & - & - & 832 & 0 & 735 & - & 1282 & - \\
\hline Qiqihaer & - & - & - & - & - & - & 735 & 0 & - & 1388 & 1803 \\
\hline Suifenhe & - & - & - & 1398 & - & 1531 & - & - & 0 & - & - \\
\hline Tongliao & - & 1061 & 1072 & - & - & - & 1282 & 1388 & - & 0 & - \\
\hline Manzhouli & - & - & - & - & - & - & - & 1803 & - & - & 0 \\
\hline
\end{tabular}


Table 6 Unit cost of an empty container in railway transport (CNY)

\begin{tabular}{|c|c|c|c|c|c|c|c|c|c|c|c|}
\hline & Dalian & Shenyang & Changchun & Yanji & Jilin & Harbin & Daqing & Qiqihaer & Suifenhe & Tongliao & Manzhouli \\
\hline Dalian & 0 & 761 & - & - & - & - & - & - & - & - & - \\
\hline Shenyang & 761 & 0 & 690 & - & 793 & - & - & - & - & 700 & - \\
\hline Changchun & - & 690 & 0 & - & 556 & 652 & 744 & - & - & 704 & - \\
\hline Yanji & - & - & - & 0 & 725 & - & - & - & 834 & - & - \\
\hline Jilin & - & 793 & 556 & 725 & 0 & 671 & - & - & - & - & - \\
\hline Harbin & - & - & 652 & - & 671 & 0 & 608 & - & 888 & - & - \\
\hline Daqing & - & - & 744 & - & - & 608 & 0 & 569 & - & 788 & - \\
\hline Qiqihaer & - & - & - & - & - & - & 569 & 0 & - & 831 & 997 \\
\hline Suifenhe & - & - & - & 834 & - & 888 & - & - & 0 & - & - \\
\hline Tongliao & - & 700 & 704 & - & - & - & 788 & 831 & - & 0 & - \\
\hline Manzhouli & - & - & - & - & - & - & - & 997 & - & - & 0 \\
\hline
\end{tabular}

Table 7 Distance between customers and container depots ( $\mathrm{km}$ ), Unit transport cost of a heavy container between customers and depots (CNY), Unit cost of an empty container between customers and depots (CNY)

\begin{tabular}{|c|c|c|c|c|}
\hline Cus No. & Depot & Distance & Cost_heavy & Cost_empty \\
\hline 1 & Dalian & 45 & 405 & 243 \\
\hline 2 & Dalian & 23 & 207 & 124.2 \\
\hline 3 & Dalian & 34 & 306 & 183.6 \\
\hline 4 & Shenyang & 15 & 135 & 81 \\
\hline 5 & Shenyang & 29 & 261 & 156.6 \\
\hline 6 & Shenyang & 43 & 387 & 232.2 \\
\hline 7 & Changchun & 45 & 405 & 243 \\
\hline 8 & Changchun & 42 & 378 & 226.8 \\
\hline 9 & Changchun & 31 & 279 & 167.4 \\
\hline 10 & Yanji & 19 & 171 & 102.6 \\
\hline 11 & Yanji & 49 & 441 & 264.6 \\
\hline 12 & Jilin & 38 & 342 & 205.2 \\
\hline 13 & Jilin & 27 & 243 & 145.8 \\
\hline 14 & Harbin & 34 & 306 & 183.6 \\
\hline 15 & Harbin & 45 & 405 & 243 \\
\hline 16 & Harbin & 21 & 189 & 113.4 \\
\hline 17 & Daqing & 17 & 153 & 91.8 \\
\hline 18 & Daqing & 32 & 288 & 172.8 \\
\hline 19 & Qiqihaer & 46 & 414 & 248.4 \\
\hline 20 & Qiqihaer & 34 & 306 & 183.6 \\
\hline 21 & Suifenhe & 47 & 423 & 253.8 \\
\hline 22 & Suifenhe & 23 & 207 & 124.2 \\
\hline 23 & Tongliao & 46 & 414 & 248.4 \\
\hline 24 & Tongliao & 17 & 153 & 91.8 \\
\hline 25 & Tongliao & 27 & 243 & 145.8 \\
\hline 26 & Manzhouli & 34 & 306 & 183.6 \\
\hline 27 & Manzhouli & 23 & 207 & 124.2 \\
\hline
\end{tabular}




\section{Funding}

This work was supported by Key Project of National Natural Science Foundation of China (71431001), the Ministry of Education of Humanities and Social Science Project of China (17YJCZH075).

\section{Authors' contributions}

$Z P$ reviewed relevant literature, designed the model and solved the model by CPLEX. HW drafted the article. WW collected the related data. YJ helped select research topic and analyzed the calculation results. All authors read and approved the final manuscript.

\section{Competing interests}

The authors declare that they have no competing interests.

\section{Publisher's Note}

Springer Nature remains neutral with regard to jurisdictional claims in published maps and institutional affiliations.

\section{Author details}

${ }^{1}$ Transportation Management College, Dalian Maritime University, Dalian 116026, People's Republic of China. ${ }^{2}$ Collaborative Innovation Center for Transport Studies, Dalian Maritime University, Liaoning, People's Republic of China. ${ }^{3}$ School of Automotive Engineering, Dalian University of Technology, Liaoning, People's Republic of China.

Received: 13 January 2018 Accepted: 17 December 2018

Published online: 24 January 2019

\section{References}

1. An F, Hu H, Xie C (2015) Service network design in inland waterway liner transportation with empty container repositioning. European Transport Research Review 7(2):9

2. Arnold P, Peeters D, Thomas I (2004) Modelling a rail/road intermodal transportation system. Transportation Research Part E: Logistics and Transportation Review 40(3):255-270

3. Bendall H, Stent A (2001) A scheduling model for a high speed containership service: A hub and spoke short-sea application. International Journal of Maritime Economics 3(3):262-277

4. Boile M, Theofanis S, Baveja A, Mittal N (2008) Regional repositioning of empty containers: Case for inland depots. Transportation Research Record: Journal of the Transportation Research Board 2066(4):31-40. https://doi.org/10.3141/2066-04

5. Bruckmann D, Dober P, Mancera A, Saabel I, Weidmann U (2016) Swiss split - a holistic approach to the distribution of containers to private sidings. European Transport Research Review 8(4):28

6. Chen C, Zeng Q (2010) Designing container shipping network under changing demand and freight rates. Transport 25(1):46-57

7. Coslovich L, Pesenti R, Ukovich W (2006) Minimizing fleet operating costs for a container transportation company. European Journal of Operational Research 171(3):776-786

8. Crainic TG, Gendreau M, Dejax P (1993) Dynamic and stochastic models for the allocation of empty containers. Operations research 41(1):102-126

9. Jiang Y, Sheu J, Peng Z, Yu B (2018) Hinterland patterns of China Railway $(\mathrm{CR})$ express in China under the Belt and Road Initiative: A preliminary analysis. Transportation Research Part E: Logistics and Transportation Review 119:189-201

10. Meng Q, Wang S (2011) Liner shipping service network design with empty container repositioning. Transportation Research Part E: Logistics and Transportation Review 47(5):695-708

11. Min H (1991) International intermodal choices via chance-constrained goal programming. Transportation Research Part A: General 25(6):351-362

12. Namboothiri R, Erera AL (2008) Planning local container drayage operations given a port access appointment system. Transportation Research Part E: Logistics and Transportation Review 44(2):185-202

13. Olivo A, Zuddas P, Di Francesco M, Manca A (2005) An operational model for empty container management. Maritime Economics \& Logistics 7(3):199-222

14. Olivo A, Zuddas P, Francesco MD, Manca A (2005) An operational model for empty container management. Maritime Economics \& Logistics 7(3):199-222
15. Rana K, Vickson R (1991) Routing container ships using lagrangean relaxation and decomposition. Transportation Science 25(3):201-214

16. Reinhardt LB, Pisinger D (2012) A branch and cut algorithm for the container shipping network design problem. Flexible Services and Manufacturing Journal 24(3):349-374

17. Shintani K, Imai A, Nishimura E, Papadimitriou S (2007) The container shipping network design problem with empty container repositioning. Transportation Research Part E: Logistics and Transportation Review 43(1):39-59

18. Song D, Zhang J, Carter J, Field T, Marshall J, Polak J, Schumacher K, Sinha-Ray P, Woods J (2005) On cost-efficiency of the global container shipping network. Maritime Policy \& Management 32(1):15-30

19. Yao BZ, Yu B, Hu P, Gao JJ, Zhang MH (2016) An improved particle swarm optimization for carton heterogeneous vehicle routing problem with a collection depot. Annals of Operations Research 242(2):303-320

20. Yu B, Shan W, Guo Z, Wang Y (2018) A heuristic algorithm based on leaf photosynthate transport. Simulation 94(7):593-607

21. Zhang R, Yun WY, Kopfer H (2010) Heuristic-based truck scheduling for inland container transportation. OR spectrum 32(3):787-808

\section{Submit your manuscript to a SpringerOpen ${ }^{\circ}$ journal and benefit from:}

- Convenient online submission

- Rigorous peer review

- Open access: articles freely available online

- High visibility within the field

- Retaining the copyright to your article

Submit your next manuscript at $>$ springeropen.com 